\title{
Low dose pig anti-influenza virus monoclonal antibodies reduce lung pathology but do not prevent virus shedding
}

Basudev Paudyal ${ }^{1}$, Adam McNee ${ }^{1}$, Pramila Rijal ${ }^{2,3}$, B. Veronica Carr ${ }^{1}$, Alejandro Nunez ${ }^{4}$, John W. McCauley ${ }^{5}$, Rodney S. Daniels ${ }^{5}$, Alain R. Townsend ${ }^{2,3}$, John A. Hammond ${ }^{1}$, Elma Tchilian ${ }^{1^{*}}$

7

8

$9 \quad{ }^{1}$ The Pirbright Institute, Pirbright GU24 ONF, UK

$10{ }^{2}$ Centre for Translational Immunology, Chinese Academy of Medical Sciences Oxford 11 Institute, University of Oxford, Oxford OX3 9DS, UK

$12{ }^{3}$ MRC Human Immunology Unit, MRC Weatherall Institute of Molecular Medicine, Radcliffe 13 Department of Medicine, University of Oxford, Oxford OX3 9DS, UK

$14{ }^{4}$ Animal and Plant Health Agency-Weybridge, New Haw, Addlestone KT15 3NB, United 15 Kingdom

${ }^{5}$ Worldwide Influenza Centre, The Francis Crick Institute, London NW1 1AT, UK

•Corresponding authors basu.paudyal@pirbight.ac.uk and elma.tchilian@pirbright.ac.uk

20

21 


\section{Abstract}

We have established the pig, a large natural host animal for influenza, with many physiological

26 similarities to humans, as a robust model for testing the therapeutic potential of monoclonal 27 antibodies (mAbs). In this study we demonstrated that prophylactic intravenous administration 28 of $15 \mathrm{mg} / \mathrm{kg}$ of porcine mAb pb18, against the $\mathrm{K} 160-163$ site of the haemagglutinin, 29 significantly reduced lung pathology and nasal virus shedding and eliminated virus from the 30 lung of pigs following $\mathrm{H} 1 \mathrm{~N} 1 \mathrm{pdm} 09$ challenge. When given at $1 \mathrm{mg} / \mathrm{kg}$, pb18 significantly 31 reduced lung pathology and lung and BAL virus loads, but not nasal shedding. Similarly, when $32 \mathrm{pb} 18$ was given in combination with pb27, which recognised the $\mathrm{K} 130$ site, at $1 \mathrm{mg} / \mathrm{kg}$ each, 33 lung virus load and pathology were reduced, although without an apparent additive or 34 synergistic effect. No evidence for mAb driven virus evolution was detected. These data 35 indicate that intravenous administration of high doses was required to reduce nasal virus 36 shedding, although this was inconsistent and seldom complete. In contrast the effect on lung 37 pathology and lung virus load is consistent and is also seen at one log lower doses, strongly 38 indicating that a lower dose might be sufficient to reduce severity of disease, but for prevention 39 of transmission other measures would be needed. 


\section{Introduction}

Influenza virus infection remains a global health threat to humans and animal influenza $A$ viruses are the CDC's top zoonotic pathogen. Pig anatomy and physiology closely resembles that of humans. They have a similar distribution of sialic acid receptors in their respiratory tract and are infected with similar influenza A viruses, making them a powerful natural host large animal model to study immunity to influenza $(1,2)$. Monoclonal antibodies (mAbs) are promising therapeutics for virus infections including influenza (3-8). We have previously shown that the strongly neutralizing human $\lg \mathrm{G} 1$ monoclonal antibody, 2-12C, administered prophylactically at $15 \mathrm{mg} / \mathrm{kg}$ to pigs, reduced virus load and lung pathology after H1N1pdm09 challenge (9). However, the study could not be extended beyond 5-6 days due to the development of anti-human IgG responses. To overcome this limitation, we have isolated porcine mAbs from H1N1pdm09 infected pigs (10). The porcine antibodies were directed towards the two major immunodominant HA epitopes - the Sa site (residues 160 and 163) and $\mathrm{Ca}$ site (residue 130), also recognized by humans. The in vitro neutralizing activity of the pig mAbs was comparable to the strongest human mAbs. One of these mAbs, pb27, targeting the same HA1 site as $2-12 \mathrm{C}$, encompassing residue $\mathrm{K} 130$, abolished lung and bronchoalveolar lavage (BAL) virus load and greatly reduced lung pathology after intravenous administration at $10 \mathrm{mg} / \mathrm{kg}$ in vivo, although nasal shedding was not eliminated (10). Interestingly when administered at a lower dose of $1 \mathrm{mg} / \mathrm{kg}$, both human 2-12C and porcine pb27 reduced significantly lung pathology and lung virus load, suggesting that potentially the cost of therapy could be greatly reduced $(9,10)$.

Here we wished to determine the potency of another porcine mAb, pb18, against the HA1 site encompassing K160, recognised by many human sera and mAbs. We tested prophylactic administration at $15 \mathrm{mg} / \mathrm{kg}$ and $1 \mathrm{mg} / \mathrm{kg}$. We also asked whether the effect of pb18 may be augmented additively or synergistically by the simultaneous administration of pb27, which targets the epitope encompassing K130.

\section{Materials and methods}

\section{Ethics statement}

Animal experiments were approved by the Pirbright institute ethics committee and Animal and Plant Health Agency (APHA) according to the UK animal (Scientific Procedures) Act 1986 under project licence P47CE0F2. Both Institutes conform to the ARRIVE guidelines. 


\section{Monoclonal antibodies}

Generation of porcine H1N1pdm09-specific mAbs were described previously (10). For animal studies, pb18 and pb27 were produced in bulk by Absolute Antibody Ltd (Redcar, UK) and dissolved in $25 \mathrm{mM}$ Histidine, $150 \mathrm{mM} \mathrm{NaCl}, 0.02 \%$ Tween, $\mathrm{pH} 6.0$ diluent.

\section{Animal Studies}

Twenty 5 weeks old, Landrace X Hampshire cross female pigs were obtained from a commercial high-health status herd and screened for antibody-free status against four swine influenza virus antigens: H1N1pdm09, H1N2, H3N2 and avian-like H1N1. Pigs weighed between $11-12 \mathrm{~kg}$ (average 10kg). Pigs were randomized into four groups of five animals as follows: the first group received $15 \mathrm{mg} / \mathrm{kg}$ of $\mathrm{pb} 18$; the second group received $1 \mathrm{mg} / \mathrm{kg}$ of $\mathrm{pb} 18$; the third group received a combination of $1 \mathrm{mg} / \mathrm{kg}$ of pb27 and $1 \mathrm{mg} / \mathrm{kg} \mathrm{pb} 18$ and; the fourth control group received PBS only. The mAbs were administered to the ear vein of animals sedated with stresnil (Janssen pharmaceuticals). Twenty-four hours after $m A b(s)$ administration, all animals were challenged intranasally with $1 \times 10^{6}$ PFUs of pandemic swine $\mathrm{H} 1 \mathrm{~N} 1$ isolate, A/swine/England/1353/2009 (H1N1pdm09) in 2ml (1ml per nostril) using a mucosal atomization device (MAD300; Wolfe Tory Medical). Clinical signs (temperature, loss of appetite, recumbence, skin haemorrhage, respiratory change, nasal discharge, altered behaviour) were observed and recorded. Clinical signs were mild and no animal developed moderate or severe disease.

\section{Gross Pathology and Histopathological scoring of Lung Lesions}

At post mortem, the lungs were removed and digital photographs taken of the dorsal and ventral aspects. Lung tissue samples from the right cranial, middle, and caudal lung lobes were excised from the lung and collected into $10 \%$ neutral buffered formalin for routine histological processing. Formalin-fixed tissues were paraffin wax-embedded and $4 \mu \mathrm{m}$ sections cut and routinely stained with haematoxylin and eosin (H\&E). Immunohistochemical detection of influenza A virus nucleoprotein (NP) was performed in $4 \mu \mathrm{m}$ tissue sections as previously described (11). Histopathological changes in the H\&E- stained lung tissue sections were scored by a veterinary pathologist blinded to the treatment group. Lung histopathology was scored using five parameters (necrosis of the bronchiolar epithelium, airway inflammation, perivascular/bronchiolar cuffing, alveolar exudates and septal inflammation) scored on a 5point scale of 0 to 4 and then summed to give a total slide score ranging from 0 to 20 per slide and a total animal score from 0 to 60 (12). The slides were also scored using the "lowa" method, that also considers the amount of virus antigen present in the sample, as described (13). 


\section{Tissue Sample processing}

107 Two nasal swabs (one per nostril) were taken each day following challenge with H1N1pdm09.

108 The swabs were placed into $2 \mathrm{ml}$ of virus transport medium (VTM) comprising tissue culture

109 medium 199 (Sigma-Aldrich) supplemented with $25 \mathrm{mM}$ 4-(2-hydroxyethyl)-1-

110 piperazineethanesulfonic acid (HEPES), $0.035 \%$ sodium bicarbonate, $0.5 \%$ bovine serum

111 albumin, penicillin $100 \mathrm{IU} / \mathrm{ml}$, streptomycin $100 \mu \mathrm{g} / \mathrm{ml}$, and nystatin $0.25 \mu \mathrm{g} / \mathrm{ml}$, vortexed,

112 centrifuged to remove debris, aliquoted and stored at $-80^{\circ} \mathrm{C}$ for subsequent virus titration.

113 Serum samples were collected at the start of the study (prior to mAb administration and 114 challenge) and at 0, 1, 3 and 4 DPI of challenge. Broncho-alveolar lavage fluid (BAL) was 115 collected from the entire left lung with $150 \mathrm{ml}$ of $0.1 \%$ BSA+PBS. BAL samples were 116 centrifuged at $300 \times g$ for $15 \mathrm{~min}$, supernatant was removed, aliquoted, and frozen for antibody 117 and virus titre analysis. The accessory lung lobes were dissected out and frozen at $-80^{\circ} \mathrm{C}$ for 118 subsequent virus titration. The whole lobe was cut into pieces and $10 \%(\mathrm{w} / \mathrm{v})$ pieces of lung 119 were homogenized in $0.1 \%$ BSA using the gentle MACS Octo dissociator, the homogenate 120 was clarified by centrifugation, and supernatant was used for virus titration.

\section{Virus titration}

122 Virus titers in nasal swabs, BAL fluid and accessory lobe were determined by plaque assay 123 on MDCK cells. The samples were 10-fold serially diluted in Dulbecco's Modified Eagle's 124 Medium (DMEM) and 200ul overlaid on confluent MDCK cells in 12 well tissue culture plates. 125 After $1 \mathrm{~h}$, the wells were washed and overlaid with $1 \mathrm{ml}$ of $0.6 \%$ agarose containing culture 126 medium with $2 \mu \mathrm{g} / \mathrm{ml}$ of TPCK (Tosyl phenylalanyl chloromethyl ketone) trypsin. Plates were 127 incubated for $48 \mathrm{~h}$ at $37^{\circ} \mathrm{C}$. Overlay was removed, and plaques were visualized by staining 128 the monolayer with $0.1 \%(\mathrm{v} / \mathrm{v})$ crystal violet and enumerated.

\section{$130 \quad$ HA gene sequencing}

131 Nasal swabs were collected in Trizol at $4 \mathrm{DPI}$ and stored at $-80^{\circ} \mathrm{C}$. Subsequently, $0.4 \mathrm{ml}$

132 aliquots were thawed and extracted with $90 \mu \mathrm{l}$ of chloroform. Following centrifugation at 12,000 $133 \mathrm{rpm} / 15 \mathrm{~min}$, the aqueous phase $(\sim 250 \mu \mathrm{l})$ was transferred to a $2 \mathrm{ml}$ Eppendorf tube and 1.5vol $134(375 \mu l) 100 \%$ ethanol added, mixed by inversion, then centrifuged briefly. The liquid was 135 transferred to a vRNA capture column (Qiagen: QIAamp viral RNA mini kit; \#52906) and

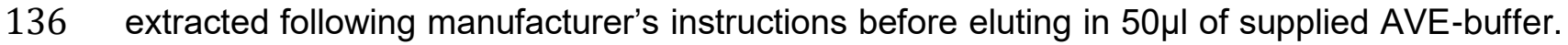
137 RT-PCRs were performed using QIAGEN OneStep ahead RT-PCR kits (\#220213) to amplify 138 HA-gene products for Sanger sequencing and whole genome products for NGS (primer 139 sequences available on request). Amplification products were then purified, sequenced, 140 curated and analysed as described recently(14). 


\section{Quantitation of mAbs in serum samples}

143 Quantification of administered mAbs, pb18 and pb27, in serum, BAL and nasal swabs was 144 determined by ELISA. Ninety-six well microtiter plates (Maxi Sorp, Nunc, sigma-Aldrich, UK) 145 were coated with $1 \mathrm{ug} / \mathrm{ml}$ of $\mathrm{HA}$ in PBS overnight at $4^{\circ} \mathrm{C}$. Plates were blocked with $200 \mu \mathrm{l}$ of 146 blocking solution composed of $4 \%$ milk powder in PBS, supplement with $0.05 \%$ Tween-20

147 (PBS-T) for $2 \mathrm{~h}$ at room temperature. A standard curve for pb18 mAb was prepared as 1:2 148 serial dilutions starting at $500 \mathrm{ng} / \mathrm{ml}$ in dilution buffer and added in duplicate to the assay plate.

149 Samples and standard were incubated for $1 \mathrm{~h}$ at room temperature. The plates were washed 150 four times with PBS-T and incubated with detecting antibodies; polyclonal goat-anti pig IgG

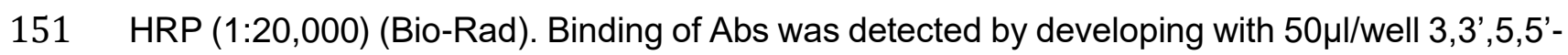
152 tetramethylbenzidine (TMB) high sensitivity substrate solution (Biolegend, UK) and stopping 153 with $50 \mu \mathrm{l} 1 \mathrm{M}$ sulphuric acid. The plates were read at 450 and $630 \mathrm{~nm}$ with the Cytation3 154 Imaging Reader (Biotek). The mAbs concentrations in samples were interpolated from the 155 standard curve using a sigmoidal four-parameter logistic curve fit for log of the concentration 156 using GraphPad Prism 8.3.

\section{Microneutralization assay}

Neutralising Antibody titres were determined in serum using a microneutralization (MN) assay.

160 Briefly, viruses were diluted in virus growth medium (VGM; DMEM-Penicillin-streptomycin$1610.1 \% \mathrm{BSA}$ ) and titrated to give plateau expression of NP in $3 \times 10^{4}$ MDCK-SIAT1 cells after 162 overnight infection in 96-well flat-bottomed plates. Serum was heat inactivated at $56^{\circ} \mathrm{C}$ for 30 $163 \mathrm{~min}$. Serum was diluted in $50 \mu$ l of VGM starting at 1:4 and serially double diluted. $50 \mu$ of 164 diluted virus was added to the serum and incubated for $1 \mathrm{~h}$ at $37^{\circ} \mathrm{C}$. In each well $100 \mu \mathrm{l}$ of $1653 \times 10^{4}$ MDCK-SIAT1 cells were added and incubated overnight at $37^{\circ} \mathrm{C}$. The monolayer was 166 fixed with 4\% paraformaldehyde and permeabilized with Triton-X100 and stained with mouse 167 anti-NP IgG1 (clone AA5H, Bio-Rad Antibodies) followed by goat anti-mouse HRP (DAKO) 168 antibody. TMB substrate was added and incubated for 2-5 min and reaction was stopped with $16950 \mu \mathrm{l}$ of $1 \mathrm{M}$ sulphuric acid and absorbance was measured at 450 and $630 \mathrm{~nm}$ (reference 170 wavelength) on the Cytation3 Imaging Reader (Biotek). The MN titre was defined as the final 171 dilution of serum that caused $\geq 50 \%$ reduction in NP expression.

\section{Statistical analysis}

173 Non-parametric unpaired two-way t-test, two-way ANOVA multiple comparisons was 174 performed using GraphPad Prism 8.3. 


\section{Results}

\section{6 mAb administration reduced virus load}

177 To determine the in vivo efficacy of porcine mAbs, pb18 was administered at $15 \mathrm{mg} / \mathrm{kg}, 1 \mathrm{mg} / \mathrm{kg}$ 178 or in combination with pb27 at $1 \mathrm{mg} / \mathrm{kg}$ each (pb18+pb27). Controls were untreated animals.

179 Twenty-four hours after mAb administration, all animals were challenged with H1N1pdm09 180 and culled at 4 days post infection (DPI) (Fig. 1A). The virus load in nasal swabs was 181 assessed daily over the 4 days by plaque assay. Nasal virus loads were significantly lowered 182 at 1,2 and $3 \mathrm{DPI}$ in the $15 \mathrm{mg} / \mathrm{kg}$ pb18 group and when assessed by the area under the curve 183 (AUC) compared to the control group ( $p=0.004$ ) (Figs. 1B and 1C). The AUC for the animals 184 treated with combined $\mathrm{pb} 18+\mathrm{pb} 27$ at $1 \mathrm{mg} / \mathrm{kg}$ was also reduced $(\mathrm{p}=0.056)$. However, $1 \mathrm{mg} / \mathrm{kg}$ 185 of pb18 alone was insufficient to reduce nasal virus shedding $(p=0.126)$. We also assessed 186 virus load in BAL and lung at 4 DPI (Fig. 1D). No virus was detected in the lungs of the $18715 \mathrm{mg} / \mathrm{kg} \mathrm{pb} 18$ and pb18+pb27 treated groups at $4 \mathrm{DPI}$, while there was virus in 2 out of 5 pigs 188 in the $1 \mathrm{mg} / \mathrm{kg}$ pb18 group. Similarly, in BAL, virus load was significantly reduced in all mAb 189 treated groups compared to controls. Overall, administration of pb18 at $15 \mathrm{mg} / \mathrm{kg} \mathrm{had} \mathrm{a}$ 190 significant effect on virus shedding and lung and BAL virus loads, while the lower doses or 191 combination of the two mAbs reduced lung virus and BAL loads. There was no evidence of 192 synergistic effect of the pb18 plus pb27 cocktail.

\section{3 mAb administration reduced lung pathology}

194 Following challenge with $\mathrm{H} 1 \mathrm{~N} 1 \mathrm{pdm} 09$, all control animals developed typical gross lung lesions 195 indicative of influenza infection by day $4 \mathrm{DPI}$, as previously reported (15). In contrast the single $19615 \mathrm{mg} / \mathrm{kg} \mathrm{pb} 18$ and combined pb18+pb27 at $1 \mathrm{mg} / \mathrm{kg}$ treated animals showed significant $197(p=0.016)$ reductions in gross pathology (Fig. 2A). In control animals, characteristic 198 histological lesions of influenza infection were observed, ranging from mild to severe 199 necrotising bronchiolitis, with weakening of the bronchial and bronchiolar epithelium and 200 neutrophilic exudation in bronchiolar lumina and alveoli. Areas of bronchointerstitial 201 pneumonia with thickening of alveolar septa and peribronchial and perivascular infiltration by 202 lymphohistiocytic cells were present. Immunolabelling for Influenza A nucleoprotein could be 203 observed in bronchial and bronchiolar epithelium, macrophages in inflammatory exudates and 204 occasional pneumocytes. The severity of these histopathological findings was assessed semi205 quantitatively using the lowa and Morgan methods (Fig. 2B). Compared to the control group, 206 all mAb treated animals showed reduced severity of the pulmonary histopathological changes 207 and lower numbers of influenza A nucleoprotein antigen immunolabelled cells (Fig 2B). 208 Although reduction in histopathology (Morgan score) was observed in all mAb treated groups, 209 this was significant $(p=0.02)$ only in the $1 \mathrm{mg} / \mathrm{kg}$ pb18 group. Significant reductions in lowa 210 score in the $15 \mathrm{mg} / \mathrm{kg} \mathrm{pb} 18(\mathrm{p}=0.02)$ and $1 \mathrm{mg} / \mathrm{kg} \mathrm{pb} 18(0.008)$ groups but not in the combined 
$211 \mathrm{pb} 18+\mathrm{pb} 27 \mathrm{mAb}$ group were also detected. In contrast to the gross pathology results, there 212 was an outlier for both Morgan and lowa scores in the control group in which the 213 histopathology scores were low. In this animal the gross lesions were mainly located in the 214 left lung (sampled only for virological analysis) and no gross lesion was present in the 215 histopathology specimen, resulting in a lower histology score and reduced statistical power 216 when comparing scores with the treatment groups.

\section{Quantitation of mAbs in serum, BAL and Nasal Secretions (NS).}

219 The concentration of administered mAbs in serum was determined by ELISA using 220 recombinant HA glycoprotein at 0, 1, 3 and 4 DPI. Peak concentrations of $215 \mu \mathrm{g} / \mathrm{ml}, 17 \mu \mathrm{g} / \mathrm{ml}$ 221 and $19 \mu \mathrm{g} / \mathrm{ml} \mathrm{pb} 18$ were detected in the $15 \mathrm{mg} / \mathrm{kg} \mathrm{pb} 18,1 \mathrm{mg} / \mathrm{kg}$ pb18 and pb18+pb27 groups, 222 respectively, at $24 \mathrm{~h}$ after administration. A decline in serum mAb concentrations was 223 observed over the next 4 days to $101 \mu \mathrm{g} / \mathrm{ml}, 9 \mu \mathrm{g} / \mathrm{ml}$, and $7 \mu \mathrm{g} / \mathrm{ml}$ respectively (Fig. 3A). BAL 224 samples showed the presence of administered mAbs; averages of $232 \mathrm{ng} / \mathrm{ml}, 9 \mathrm{ng} / \mathrm{ml}$ and $22518 \mathrm{ng} / \mathrm{ml}$ for $15 \mathrm{mg} / \mathrm{kg} \mathrm{pb} 18,1 \mathrm{mg} / \mathrm{kg} \mathrm{pb} 18$ and pb18+pb27 groups, respectively, were 226 observed at $4 \mathrm{DPI}$. The administered mAbs were detected in nasal swabs at $4 \mathrm{DPI}$. We also 227 analysed the neutralizing activity of the mAbs in serum and BAL. In serum, there were $50 \%$ 228 inhibition neutralizing titers of $1: 23,000,1: 1,200$ and $1: 2,900$ for $15 \mathrm{mg} / \mathrm{kg} \mathrm{pb} 18,1 \mathrm{mg} / \mathrm{kg}$ pb18 229 and pb18+pb27 groups, respectively, after $24 \mathrm{~h}$ of administration which gradually declined 230 over the next four days (Fig. 3B). Microneutralization titers closely corresponded to the level 231 of mAb in serum. Neutralizing activity in BAL was seen in all animals of the $15 \mathrm{mg} / \mathrm{kg} \mathrm{pb} 18$ 232 group, in three animals administered $1 \mathrm{mg} / \mathrm{kg}$ of both pb18 and pb27, but in no animals of the $2331 \mathrm{mg} / \mathrm{kg}$ pb18 group. The latter, probably relates to the lavage procedure which greatly dilutes 234 the fluid present in airways.

236 Sequencing of virus: The stock of challenge virus and viruses from the nasal swabs of all 20 237 experimental animals were subjected to Sanger and whole genome sequencing with a focus 238 on the HA gene. Complete HA gene sequences were recovered for the challenge virus and 239 from 15 of the 20 animal specimens (Table 1). The challenge virus showed polymorphism at 240 three positions in HA1, 154, 155 and 209. The dominant amino acid at these three positions 241 (K154, G155 and E209) was non-polymorphic in in 15, 12 and 10 of the experimental animal 242 specimens, respectively, and remained the dominant amino acid in all but one of these 243 specimens. Animal 3194 in the $15 \mathrm{mg} / \mathrm{kg}$ pb18 group showed dominance of E155 and K209, 244 and A186T substitution. Two additional animals in the $15 \mathrm{mg} / \mathrm{kg}$ pb18 group, 3190 and 3192 , 245 showed polymorphism at HA1 positions 184 and 186, or HA2 V201A substitution, respectively. 
246 One animal each in the $1 \mathrm{mg} / \mathrm{kg} \mathrm{pb} 18, \mathrm{p} 18+\mathrm{p} 27$ and the no mAb groups yielded sequences

247 that showed polymorphism at HA1 position 222.

\section{Discussion}

250 In this study we demonstrated that prophylactic intravenous administration of porcine mAb $251 \mathrm{pb} 18$ at $15 \mathrm{mg} / \mathrm{kg}$ significantly reduced lung pathology and nasal virus shedding, and abolished 252 lung virus load in pigs following H1N1pdm09 challenge. When given at $1 \mathrm{mg} / \mathrm{kg}$, pb18 253 significantly reduced lung gross and histopathology and lung and BAL virus loads, but not 254 nasal shedding of virus. Similarly, when pb18 was given in combination with pb27 at $1 \mathrm{mg} / \mathrm{kg}$ 255 each, lung virus load and pathology were reduced, although without an apparent additive or 256 synergistic effect. The challenge virus showed amino acid polymorphism at three positions 257 (154, 155 and 209) in HA1 and additional polymorphism or substitution was seen at positions 258184,186 or 222 in some of the samples from experimental animals. While there was no 259 evidence for direct mAb driven evolution of the virus HA gene in any of the experimental 260 animals, amino acid substitutions at the equivalents of all six of these positions have been associated with antigenic drift/mAb escape and/or changes in receptor specificity/host range in at least one influenza A HA subtype. Notably, substitutions at positions 155 (16-19), 186 (20-22), 209 (23) and $222(24,25)$ in the $\mathrm{HA}$ of $\mathrm{A}(\mathrm{H} 1 \mathrm{~N} 1)$ pdm09 viruses have been associated with such effects. The apparent lack of mAb driven HA evolution may partly be explained by the fact that samples were taken at only $4 \mathrm{DPI}$ and tight bottlenecks may occur with very few viruses initiating infection (26). Such a scenario could explain the HA sequence derived from animal 3194 with HA1 G155E, A186T and E209K amino acid substitutions, the infecting virus being a minor variant within the $\mathrm{A} /$ swine/England/1353/2009 challenge virus stock.

The present data are in agreement with our previous experience with the human 2$12 \mathrm{C}$ and porcine pb27 mAbs in similar challenge experiments $(9,10)$. Intravenous administration of high doses $(15 \mathrm{mg} / \mathrm{kg}$ or $10 \mathrm{mg} / \mathrm{kg}$ ) was required to reduce nasal virus shedding, although this was inconsistent and seldom complete, as in the present experiment.

273 In contrast the effect on lung pathology and lung virus load is consistent and is also seen at 274 one log lower doses in all experiments. This strongly indicates that a lower dose might be 275 sufficient to reduce severity of disease, but for prevention of transmission other measures 276 would be needed. It may be that a different IgG subclass or local administration to the 277 respiratory tract would be more effective in supressing nasal virus shedding (27). Furthermore 278 it is interesting to note that the effect of low dose mAb in reducing lung pathology, but not virus 279 shedding is very similar to the effect of the powerful influenza specific CD8 responses induced 280 by S-FLU immunisation $(28,29)$. This contrasts strongly with the effect of cytotoxic $T$ cells in 281 mice, which have been shown to protect both against disease (weight loss) and to reduce viral 282 load (30-32), whereas in pigs a powerful T cell response or in this case mAb are insufficient 
283

284

285

286

287

288

289

290

291

292

293

294

295

296

297

298

299

300

301

302

303

304

305

306

307

308

309

310

311

312

313 Acknowledgements: We are grateful to the veterinarians, pathologists and animal staff at

to protect the upper respiratory tract from infection and shedding, although the lung viral load and pathology are reduced. This is an important difference between large and small animal models and it will be important be determine which best predicts the outcome of therapy in humans.

There was no evidence for a synergistic or additive effect for the pb18 and pb27 cocktail, although the mAbs targeted different epitopes. There is already a large literature on attempts to improve efficacy of mAbs by administering them as cocktails, which may result in lowered infection rates and virus loads, thereby reducing the probability of neutralizationescape variants emerging (33-36). While mAb cocktails alone have not proved effective in influenza, combination therapy with the viral polymerase inhibitor favipiravir and $m A b s$ against the receptor-binding site and stem of virus HA completely stopped virus replication in nude mice, resulting in virus clearance $(6,37,38)$. Administration of both anti-HA and anti-NA antibodies might also be effective and further studies to define whether the pigs generate broadly inhibiting anti-NA antibodies as has been shown in humans would allow us to test how protective these are in vivo (39). High-resolution structures revealed a mechanism of cooperativity in Ebola virus (EBOV) mAb cocktails (40). A two-antibody cocktail offered protection in mice against the most antigenically divergent virus and demonstrated high therapeutic efficacy against live EBOV challenge in non-human primates. These findings offered a rational strategy for development of a potent two-antibody cocktail design based on structural features of $\mathrm{mAb}$ interactions with EBOV. However in other systems molecular interactions in which two or more mAbs recognize the same antigen synergistically are poorly defined, but these interactions might contribute greatly to the overall efficacy of protective $\mathrm{mAb}$ cocktails (41-44).

In summary we showed that the pig is a useful model to test mAb delivery and efficacy, particularly for influenzas virus, since pigs are infected by the same H1N1pdm09 influenza A viruses as humans and we have shown that pigs mount very similar antibody responses to the virus HA as seen in humans. The lobar and bronchial structure of the pig lung is very like that of humans and here we showed that a low dose of mAb may be highly effective in preventing lung pathology and severe disease.

APHA for providing excellent animal care and support during post-mortem sampling and to Helen Everett for her scientific support. We thank APHA for providing the swine A/Sw/Eng/1353/2009 influenza virus strain (DEFRA and devolved administrations of Scotland and Wales surveillance programme SV3041). 
319 Funding: This work was supported by Bill \& Melinda Gates Foundation grant OPP1201470 and 320 OPP1215550 (Pirbright Livestock Antibody Hub); UKRI Biotechnology and Biological Sciences

321 Research Council (BBSRC) grants BBS/E//00007031, BBS/E///00007038 and

$322 \mathrm{BBS} / \mathrm{E} / \mathrm{I} / 00007039$. ART and PR were funded by the Chinese Academy of Medical Sciences

323 (CAMS) Innovation Fund for Medical Sciences (CIFMS), China Grant 2018-I2M-2-002, the

324 Townsend-Jeantet Prize Charitable Trust (charity number 1011770) and the Medical Research

325 Council (MRC) Grant MR/P021336/1. The Worldwide Influenza Centre is supported by the

326 Francis Crick Institute receiving core funding from Cancer Research UK (FC001030), the

327 Medical Research Council (FC001030) and the Wellcome Trust (FC001030).

329 Author contributions: ET, BP, AT, JH conceived, designed and coordinated the study. BP, 330 AM, VC, performed animal experiments, processed samples and analyzed the data. AN 331 carried out postmortem and pathological analyses; AT and PR designed experiments, 332 provided reagents and developed assays for assessment of antibody function RD, JM 333 performed sequencing analysis; ET, BP, PR and RD wrote and revised the manuscript. 
334

335

336

337

338

339

340

341

342

343

344

345

346

347

348

349

350

351

352

353

354

355

356

357

358

359

360

361

362

363

364

365

366

367

368

369

370

371

372

373

374

375

376

377

378

379

380

381

\section{References:}

1. Judge EP, Hughes JM, Egan JJ, Maguire M, Molloy EL, O'Dea S. Anatomy and bronchoscopy of the porcine lung. A model for translational respiratory medicine. Am J Respir Cell Mol Biol. 2014;51(3):334-43.

2. Rajao DS, Vincent AL. Swine as a model for influenza A virus infection and immunity. ILAR J. 2015;56(1):44-52.

3. Corti D, Voss J, Gamblin SJ, Codoni G, Macagno A, Jarrossay D, et al. A neutralizing antibody selected from plasma cells that binds to group 1 and group 2 influenza A hemagglutinins. Science (New York, NY). 2011;333(6044):850-6.

4. Dreyfus C, Laursen NS, Kwaks T, Zuijdgeest D, Khayat R, Ekiert DC, et al. Highly conserved protective epitopes on influenza B viruses. Science. 2012;337(6100):1343-8.

5. Bangaru S, Lang S, Schotsaert M, Vanderven HA, Zhu X, Kose N, et al. A Site of Vulnerability on the Influenza Virus Hemagglutinin Head Domain Trimer Interface. Cell. 2019;177(5):1136-52.e18.

6. Ali SO, Takas T, Nyborg A, Shoemaker K, Kallewaard NL, Chiong R, et al. Evaluation of MEDI8852, an Anti-Influenza A Monoclonal Antibody, in Treating Acute Uncomplicated Influenza. Antimicrob Agents Chemother. 2018;62(11).

7. Deng R, Lee AP, Maia M, Lim JJ, Burgess T, Horn P, et al. Pharmacokinetics of MHAA4549A, an Anti-Influenza A Monoclonal Antibody, in Healthy Subjects Challenged with Influenza A Virus in a Phase IIa Randomized Trial. Clin Pharmacokinet. 2018;57(3):367-77.

8. Sparrow E, Friede M, Sheikh M, Torvaldsen S, Newall AT. Passive immunization for influenza through antibody therapies, a review of the pipeline, challenges and potential applications. Vaccine. 2016;34(45):5442-8.

9. McNee A, Smith TRF, Holzer B, Clark B, Bessell E, Guibinga G, et al. Establishment of a Pig Influenza Challenge Model for Evaluation of Monoclonal Antibody Delivery Platforms. J Immunol. 2020.

10. Holzer B, Rijal P, McNee A, Paudyal B, Martini V, Clark B, et al. Protective porcine influenza virus-specific monoclonal antibodies recognize similar haemagglutinin epitopes as humans. PLoS Pathog. 2021;17(3):e1009330.

11. Vidaña B, Martínez J, Martínez-Orellana P, García Migura L, Montoya M, Martorell $\mathrm{J}$, et al. Heterogeneous pathological outcomes after experimental pH1N1 influenza infection in ferrets correlate with viral replication and host immune responses in the lung. Vet Res. 2014;45:85.

12. Morgan SB, Hemmink JD, Porter E, Harley H, Holly H, Aramouni M, et al. Aerosol Delivery of a Candidate Universal Influenza Vaccine Reduces Viral Load in Pigs Challenged with Pandemic H1N1 Virus. J Immunol. 2016;196(12):5014-23.

13. Gauger PC, Vincent AL, Loving CL, Henningson JN, Lager KM, Janke BH, et al. Kinetics of lung lesion development and pro-inflammatory cytokine response in pigs with vaccine-associated enhanced respiratory disease induced by challenge with pandemic (2009) A/H1N1 influenza virus. Veterinary pathology. 2012;49(6):900-12.

14. Daniels RS, Tse H, Ermetal B, Xiang Z, Jackson DJ, Guntoro J, et al. Molecular Characterization of Influenza C Viruses from Outbreaks in Hong Kong SAR, China. J Virol. 2020;94(21):e01051-20.

15. Brookes SM, Irvine RM, Nunez A, Clifford D, Essen S, Brown IH, et al. Influenza A (H1N1) infection in pigs. The Veterinary record. 2009;164(24):760-1.

16. Tapia R, Torremorell M, Culhane M, Medina RA, Neira V. Antigenic characterization of novel H1 influenza A viruses in swine. Sci Rep. 2020;10(1):4510-. 
17. Nguyen HKL, Nguyen PTK, Nguyen TC, Hoang PVM, Le TT, Vuong CD, et al. Virological characterization of influenza H1N1pdm09 in Vietnam, 2010-2013. Influenza and Other Respiratory Viruses. 2015;9(4):216-24.

18. Lee N, Khalenkov AM, Lugovtsev VY, Ireland DD, Samsonova AP, Bovin NV, et al. The use of plant lectins to regulate H1N1 influenza A virus receptor binding activity. PLoS One. 2018;13(4):e0195525.

19. Ilyushina NA, Komatsu TE, Ince WL, Donaldson EF, Lee N, O'Rear JJ, et al. Influenza A virus hemagglutinin mutations associated with use of neuraminidase inhibitors correlate with decreased inhibition by anti-influenza antibodies. Virol J. 2019;16(1):149. 20. Zolotarova O, Budzanivska I, Leibenko L, Radchenko L, Mironenko A. Antigenic Site Variation in the Hemagglutinin of Pandemic Influenza A(H1N1)pdm09 Viruses between 2009-2017 in Ukraine. Pathogens. 2019;8(4).

21. Yasugi M, Kubota-Koketsu R, Yamashita A, Kawashita N, Du A, Misaki R, et al. Emerging antigenic variants at the antigenic site Sb in pandemic A(H1N1)2009 influenza virus in Japan detected by a human monoclonal antibody. PLoS One. 2013;8(10):e77892. 22. Houng H-SH, Garner J, Zhou Y, Lyons A, Kuschner R, Deye G, et al. Emergent 2009 influenza $A(H 1 N 1)$ viruses containing HA D222N mutation associated with severe clinical outcomes in the Americas. J Clin Virol. 2012;53(1):12-5.

23. Wang W, Lu J, Cotter CR, Wen K, Jin H, Chen Z. Identification of critical residues in the hemagglutinin and neuraminidase of influenza virus H1N1pdm for vaccine virus replication in embryonated chicken eggs. J Virol. 2013;87(8):4642-9.

24. Liu Y, Childs RA, Matrosovich T, Wharton S, Palma AS, Chai W, et al. Altered receptor specificity and cell tropism of $\mathrm{D} 222 \mathrm{G}$ hemagglutinin mutants isolated from fatal cases of pandemic A(H1N1) 2009 influenza virus. J Virol. 2010;84(22):12069-74.

25. Belser JA, Jayaraman A, Raman R, Pappas C, Zeng H, Cox NJ, et al. Effect of D222G Mutation in the Hemagglutinin Protein on Receptor Binding, Pathogenesis and Transmissibility of the 2009 Pandemic H1N1 Influenza Virus. PLOS ONE. 2011;6(9):e25091.

26. McCrone JT, Woods RJ, Martin ET, Malosh RE, Monto AS, Lauring AS. Stochastic processes constrain the within and between host evolution of influenza virus. Elife. 2018;7.

27. Vigil A, Frias-Staheli N, Carabeo T, Wittekind M. Airway Delivery of Anti-influenza Monoclonal Antibodies Results in Enhanced Antiviral Activities and Enables BroadCoverage Combination Therapies. J Virol. 2020;94(22):e00052-20.

28. Martini V, Paudyal B, Chrun T, McNee A, Edmans M, Atangana Maze E, et al. Simultaneous Aerosol and Intramuscular Immunization with Influenza Vaccine Induces Powerful Protective Local T Cell and Systemic Antibody Immune Responses in Pigs. J Immunol. 2021;206(3):652-63.

29. Holzer B, Morgan SB, Matsuoka Y, Edmans M, Salguero FJ, Everett H, et al. Comparison of Heterosubtypic Protection in Ferrets and Pigs Induced by a Single-Cycle Influenza Vaccine. J Immunol. 2018;200(12):4068-77.

30. Teijaro JR, Turner D, Pham Q, Wherry EJ, Lefrançois L, Farber DL. Cutting edge: Tissue-retentive lung memory CD4 $\mathrm{T}$ cells mediate optimal protection to respiratory virus infection. J Immunol. 2011;187(11):5510-4.

31. Wu T, Hu Y, Lee YT, Bouchard KR, Benechet A, Khanna K, et al. Lung-resident memory CD8 $\mathrm{T}$ cells (TRM) are indispensable for optimal cross-protection against pulmonary virus infection. J Leukoc Biol. 2014;95(2):215-24. 

Cells Provide Antigen-Specific Protection against Respiratory Virus Challenge through Rapid IFN- $\gamma$ Production. J Immunol. 2015;195(1):203-9.

33. Corti D, Misasi J, Mulangu S, Stanley DA, Kanekiyo M, Wollen S, et al. Protective monotherapy against lethal Ebola virus infection by a potently neutralizing antibody. Science. 2016;351(6279):1339-42.

435

436

34. Corti D, Passini N, Lanzavecchia A, Zambon M. Rapid generation of a human monoclonal antibody to combat Middle East respiratory syndrome. J Infect Public Health. 2016;9(3):231-5.

438 35. Keeffe JR, Van Rompay KKA, Olsen PC, Wang Q, Gazumyan A, Azzopardi SA, et al. A 439 Combination of Two Human Monoclonal Antibodies Prevents Zika Virus Escape Mutations in Non-human Primates. Cell Rep. 2018;25(6):1385-94.e7. 36. Wec AZ, Bornholdt ZA, He S, Herbert AS, Goodwin E, Wirchnianski AS, et al. Development of a Human Antibody Cocktail that Deploys Multiple Functions to Confer Pan-Ebolavirus Protection. Cell Host Microbe. 2019;25(1):39-48.e5.

37. Kiso M, Yamayoshi S, Kawaoka Y. Triple combination therapy of favipiravir plus two monoclonal antibodies eradicates influenza virus from nude mice. Commun Biol. 2020;3(1):219.

38. Principi N, Camilloni B, Alunno A, Polinori I, Argentiero A, Esposito S. Drugs for Influenza Treatment: Is There Significant News? Frontiers in Medicine. 2019;6(109).

450 39. Rijal P, Wang BB, Tan TK, Schimanski L, Janesch P, Dong T, et al. Broadly Inhibiting Antineuraminidase Monoclonal Antibodies Induced by Trivalent Influenza Vaccine and H7N9 Infection in Humans. J Virol. 2020;94(4).

40. Gilchuk P, Murin CD, Milligan JC, Cross RW, Mire CE, Ilinykh PA, et al. Analysis of a Therapeutic Antibody Cocktail Reveals Determinants for Cooperative and Broad Ebolavirus Neutralization. Immunity. 2020;52(2):388-403.e12.

41. Carlsen TH, Pedersen J, Prentoe JC, Giang E, Keck ZY, Mikkelsen LS, et al. Breadth of neutralization and synergy of clinically relevant human monoclonal antibodies against HCV genotypes 1a, 1b, 2a, 2b, 2c, and 3a. Hepatology. 2014;60(5):1551-62.

42. Doria-Rose NA, Louder MK, Yang Z, O'Dell S, Nason M, Schmidt SD, et al. HIV-1 neutralization coverage is improved by combining monoclonal antibodies that target independent epitopes. J Virol. 2012;86(6):3393-7.

43. Howell KA, Brannan JM, Bryan C, McNeal A, Davidson E, Turner HL, et al. Cooperativity Enables Non-neutralizing Antibodies to Neutralize Ebolavirus. Cell Rep. 2017;19(2):413-24.

466

467

468

44. Mascola JR, Louder MK, VanCott TC, Sapan CV, Lambert JS, Muenz LR, et al. Potent and synergistic neutralization of human immunodeficiency virus (HIV) type 1 primary isolates by hyperimmune anti-HIV immunoglobulin combined with monoclonal antibodies 2F5 and 2G12. J Virol. 1997;71(10):7198-206.

45. Hong M, Lee PS, Hoffman RMB, Zhu X, Krause JC, Laursen NS, et al. Antibody Recognition of the Pandemic H1N1 Influenza Virus Hemagglutinin Receptor Binding Site. J Virol. 2013;87(22):12471-80. 
A)

1. $\mathrm{pb} 18-15 \mathrm{mg} / \mathrm{kg}$

2. $\mathrm{pb} 18-1 \mathrm{mg} / \mathrm{kg}$

3. $1 \mathrm{mg} / \mathrm{kg} \mathrm{pb} 18+1 \mathrm{mg} / \mathrm{kg} \mathrm{pb} 27$

4. control

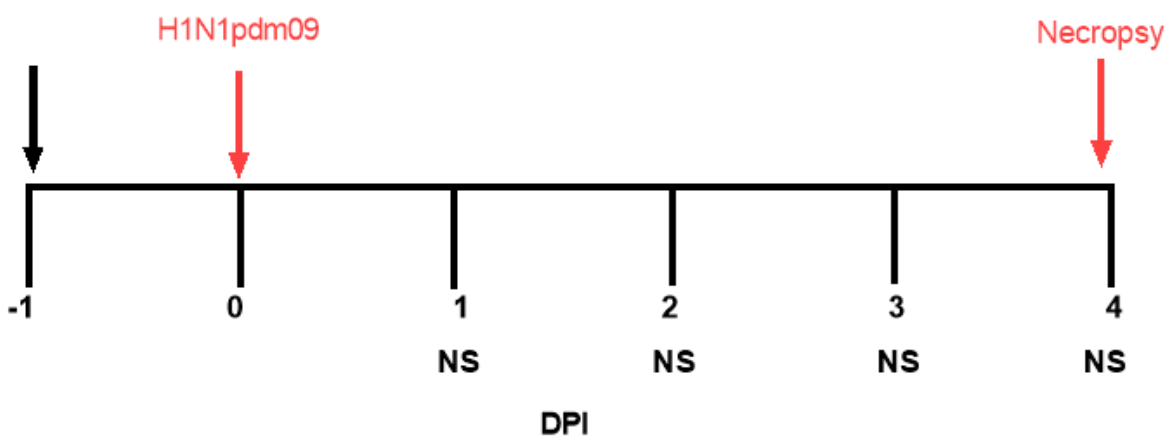

B)

NS-1 DPI

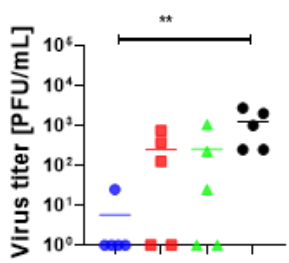

C)

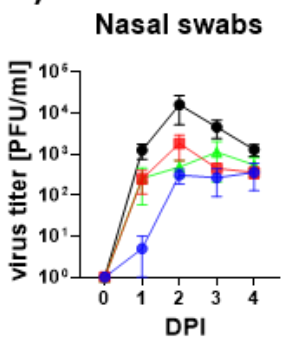

NS-2 DPI

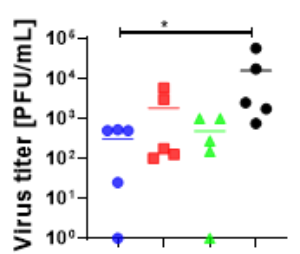

D)

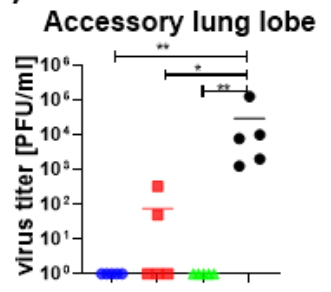

NS-3 DPI
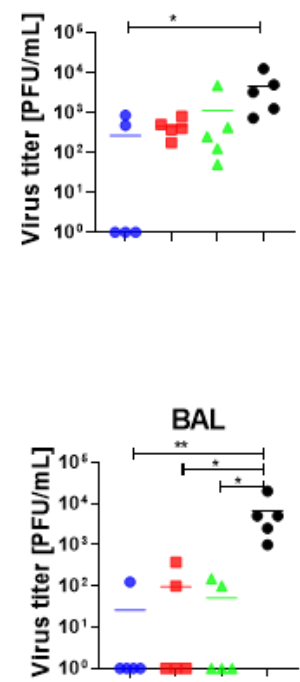

NS-4 DPI

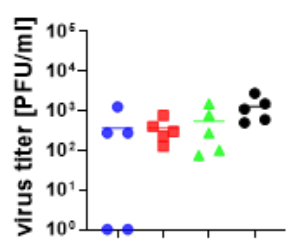

- $15 \mathrm{mg} / \mathrm{kg} \mathrm{pb} 18$

- $1 \mathrm{mg} / \mathrm{kg} \mathrm{pb} 18$

$\Delta \quad 1 \mathrm{mg} / \mathrm{kg} \mathrm{pb} 18+1 \mathrm{mg} / \mathrm{kg} \mathrm{pb} 27$

- control
472

473

474

475

476

477

478

479

480

481

482

483
Figure 1: Experimental design and virus load. pb18 was administered at $15 \mathrm{mg} / \mathrm{kg}, 1 \mathrm{mg} / \mathrm{kg}$ or simultaneously with pb27 at $1 \mathrm{mg} / \mathrm{kg}$ each to pigs which were challenged with $\mathrm{H} 1 \mathrm{~N} 1 \mathrm{pdm} 09$ virus 24 hours later. The control group animals received PBS before infection. Nasal swabs were taken at 0, 1, 2, 3 and $4 \mathrm{DPI}$, and the pigs were culled at $4 \mathrm{DPI}$ (A). Virus load in daily NS (B) and over time (C), accessory lung and BAL at 4 DPI (D) were determined by plaque assay. Each data point represents an individual within the indicated group and bars show SEM. The significance is indicated against the control. Asterisks denote significant differences ${ }^{*} p<0.05,{ }^{* *} p<0.01 .{ }^{* *} p<0.001$, versus control as analysed by the one-way ANOVA KruskalWallis test. 
A)
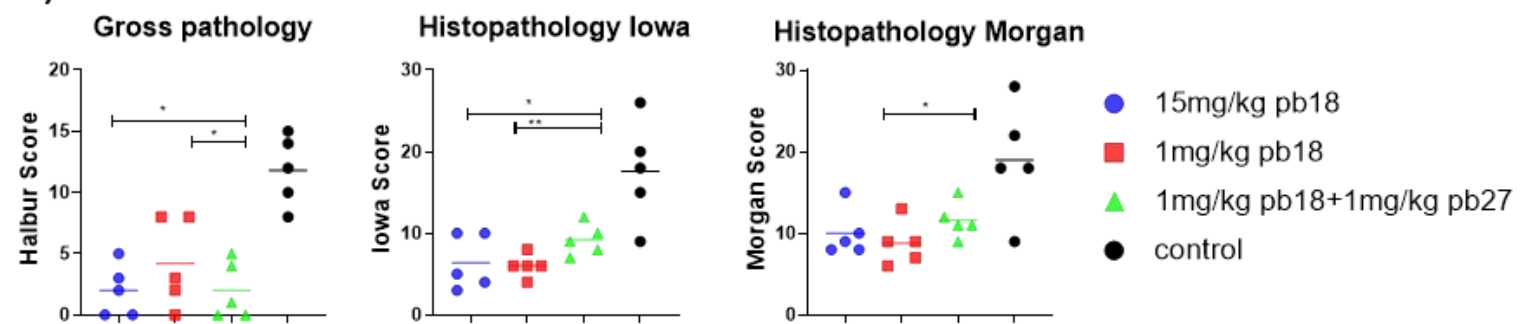

B)

Gross pathology

$H \& E$

NP IHC staining

$15 \mathrm{mg} / \mathrm{kg}$
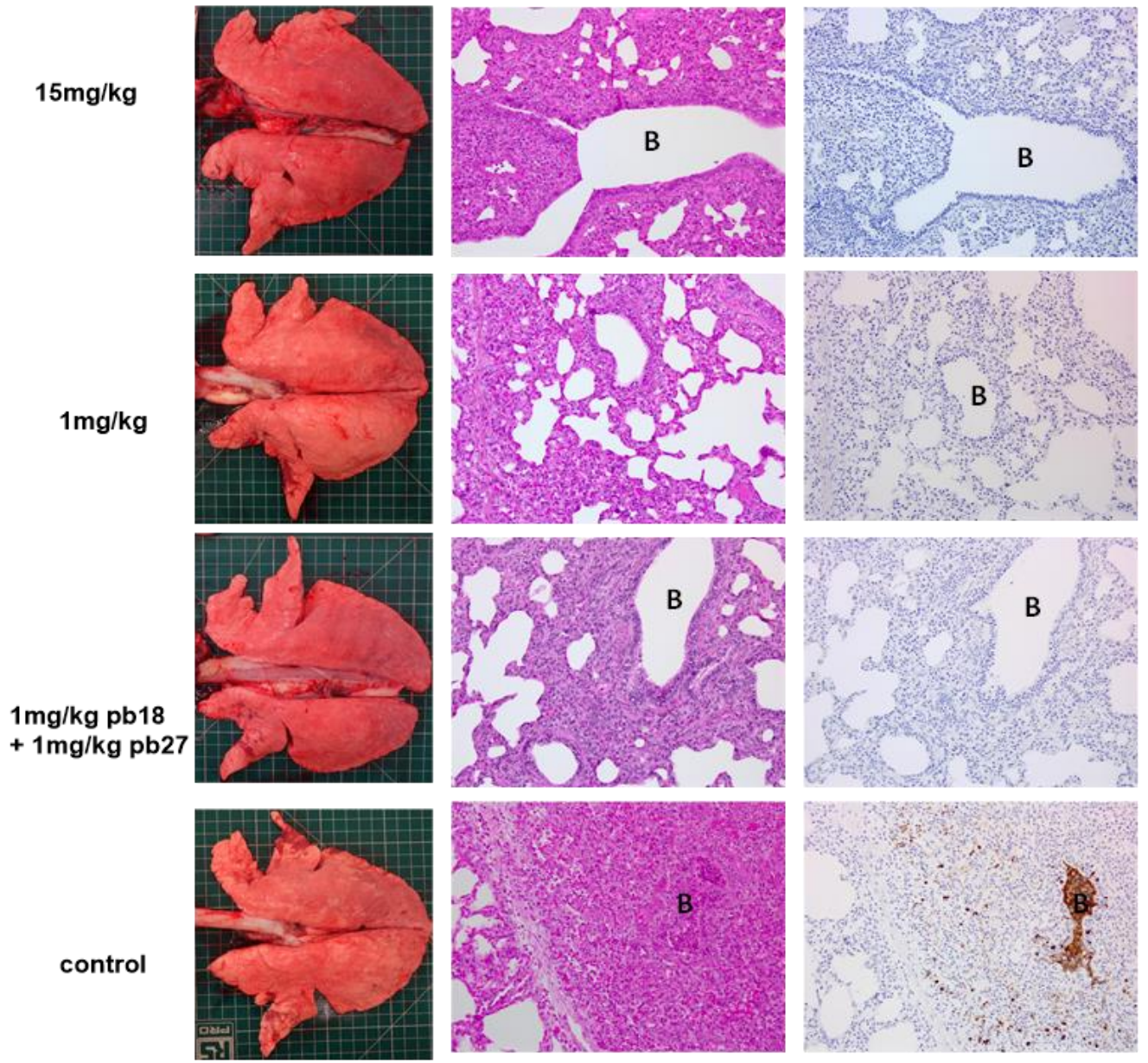

Figure 2: Lung pathology. pb18 was administered at $15 \mathrm{mg} / \mathrm{kg}, 1 \mathrm{mg} / \mathrm{kg}$ or simultaneously with pb27 at $1 \mathrm{mg} / \mathrm{kg}$ each to pigs which were challenged with H1N1pdm09 virus 24 hours later. The control group animals received PBS before infection. The animals were culled four days later and the lung scored for appearance of gross and histopathology lesions. The gross and histopathology scores for each individual in a group and the group means are shown (A). Representative gross pathology, histopathology (H\&E staining; original magnification 100x), and immunohistochemical NP staining (original magnification 200x) for each group are shown (B), bronchiole region depicted at "B" the lesion scores and the histopathological scores (includes the NP staining). Pathology scores were analyzed using the one-way non-parametric ANOVA Kruskal-Wallis test. Asterisks denote significant differences ${ }^{*} p<0.05$, ${ }^{* *} p<0.01$ versus control. 
A)

ELISA-Serum

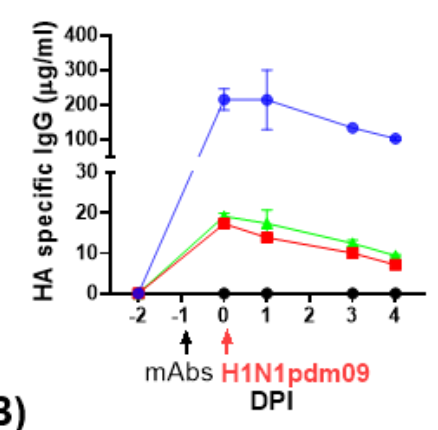

MN-Serum

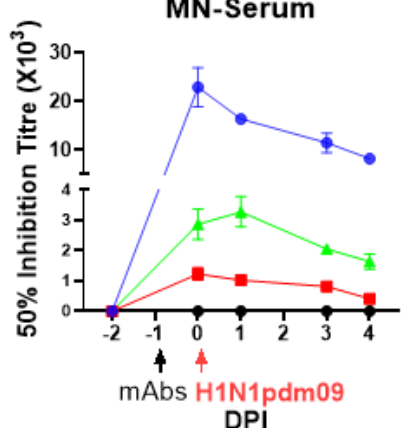

DPI
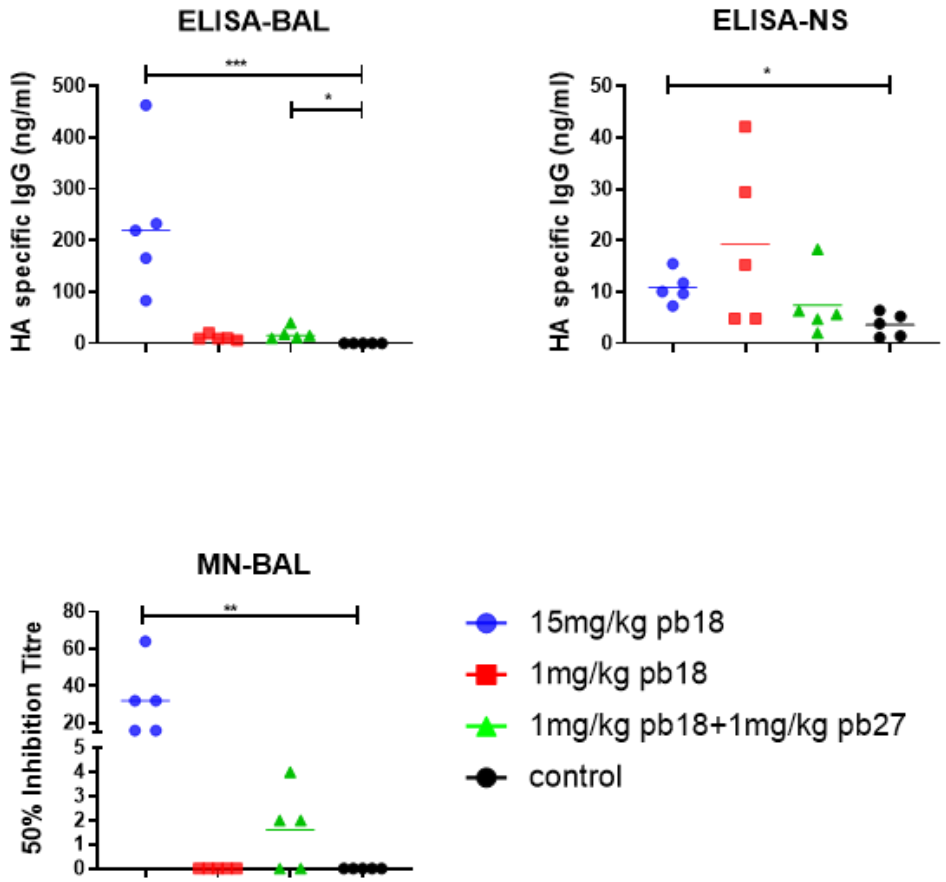

499
Figure 3: Concentration and neutralization titers of mAbs in serum, BAL and nasal swabs. HA specific IgG in serum was assessed by ELISA at the indicated DPI and in BAL and nasal swabs at $4 \mathrm{DPI}(\mathbf{A})$. The $50 \%$ neutralization titers against $\mathrm{H} 1 \mathrm{~N} 1 \mathrm{pdm} 09$ in sera at the indicated timepoints and in BAL at $4 \mathrm{DPI}$ are shown (B). Symbols represent individual pigs within the indicated group and the lines represent SEM. Data were analyzed using the oneway non-parametric ANOVA Kruskal-Wallis test. Asterisks denote significant differences ${ }^{*} p<0.05,{ }^{* *} p<0.01,{ }^{* * *} p<0.001$ versus control. 

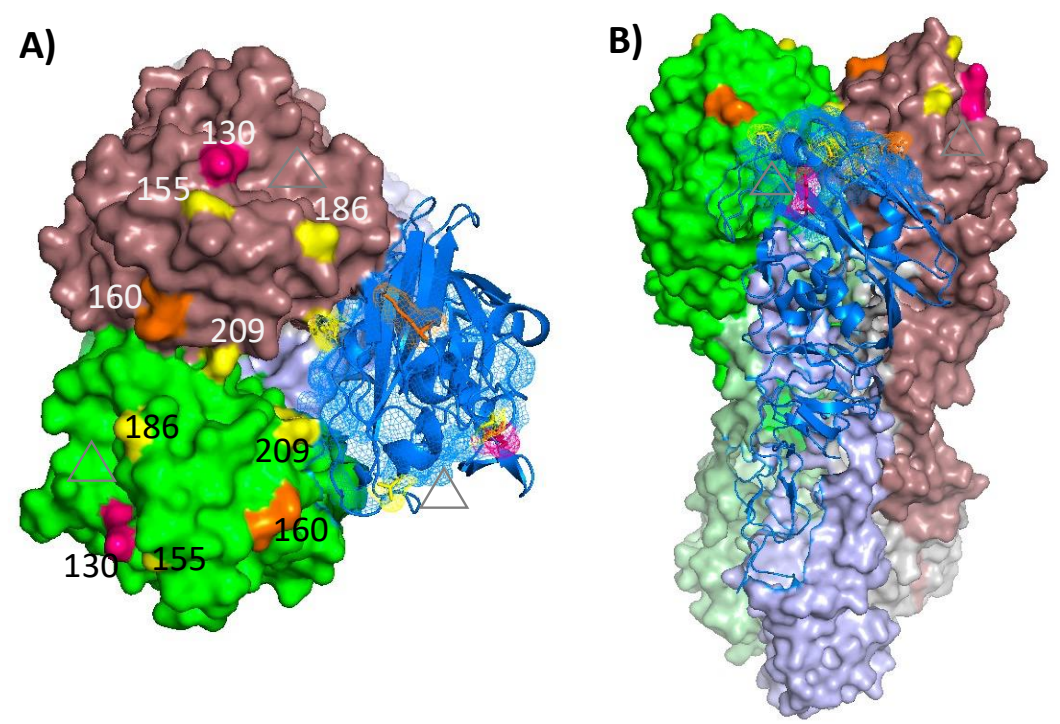

509

510 Figure 4: HA1 residues within the mAb binding sites. Residues that undergo substitution 511 in mAb-escape variants are indicated: for pb27 K130 is indicated in pink and for pb18 K160 is indicated in orange. The HA amino acid variation in viruses (G155E, A186T and E209K) recovered from experimental animals are indicated in yellow. A) Top view, with sialic-acid binding sites indicated with gray triangles. B) Lateral view. In both views two monomers are shown in surface views, while the HA1 component of the third monomer gives a secondary structure view. Images were made using Pymol2 on PDB 4M4Y (45). 


\section{Table 1: Virus HA amino acid variation in viruses recovered from experimental animals.}

518 Complete HA gene sequences were recovered for 15 of the experimental animals and the $519 \mathrm{~A} /$ swine/England/1353/2009 challenge virus stock. Only positions that differ from the 520 challenge virus are indicated. *Residues where amino acid polymorphism was seen in at least 521 one virus. "Sequences recovered by Sanger sequencing only where a cut-off of an amino acid 522 representing $\geq 80 \%$ of the population was considered to represent no polymorphism (26).

\begin{tabular}{|c|c|c|c|c|c|c|c|c|}
\hline HA1 (HA2) amino acid position & $154^{*}$ & $155^{*}$ & 184 & $186^{*}$ & $209 *$ & $222 *$ & $(201)$ & Animalno \\
\hline Challenge stock amino acid & $X($ K65:E35) & $\mathrm{X}(\mathrm{G} 95: \mathrm{E} 5)$ & $\mathrm{T}$ & $\mathrm{A}$ & $\mathrm{X}(\mathrm{E} 60: \mathrm{K} 40)$ & G & $\mathrm{V}$ & parminar \\
\hline \multirow[t]{4}{*}{$15 \mathrm{mg} / \mathrm{kg}$ pb18 group } & K & G & T97:17 & A30:T70 & $E$ & & & 3190 \\
\hline & K & G & & & $\mathrm{E}$ & & A & 3192 \\
\hline & K & $\mathrm{E}$ & & $\mathrm{T}$ & K & & & $3194^{\#}$ \\
\hline & K & G. & & & $E$ & & & 3206 \\
\hline \multirow[t]{4}{*}{$1 \mathrm{mg} / \mathrm{kg}$ pb18 group } & K & G & & & $\mathrm{E}$ & & & 3195 \\
\hline & K & G & & & $\mathrm{E}$ & & & 3196 \\
\hline & K & G & & & $\mathrm{E}$ & & & 3197 \\
\hline & K & G. & & & E70:K30 & G92:V8 & & 3199 \\
\hline \multirow[t]{2}{*}{$1 \mathrm{mg} / \mathrm{kg}$ each pb18+pb27 group } & K & G & & & $\mathrm{E}$ & & & 3200 \\
\hline & K & G & & & $E$ & G60:D40 & & 3201 \\
\hline \multirow[t]{5}{*}{ no $\mathrm{mAb}$ (control) group } & $\mathrm{K}$ & G & & & E91:K9 & & & 3205 \\
\hline & K & G & & & $E$ & & & 3207 \\
\hline & K & G & & & $\mathrm{E}$ & & & 3208 \\
\hline & K & G55:E45 & & & E55:K45 & & & $3209^{\#}$ \\
\hline & K & G85:E15 & & & E87:K13 & G94:D6 & & 3191 \\
\hline
\end{tabular}


H1N1pdm09

Necropsy

7

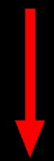

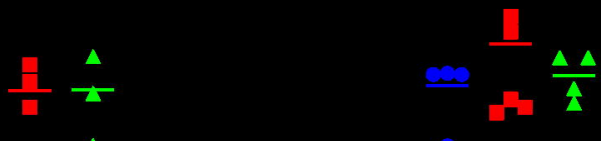

$8-\frac{\Delta}{\Delta \Delta}$

$=\frac{\hat{x}}{\Delta}$

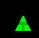

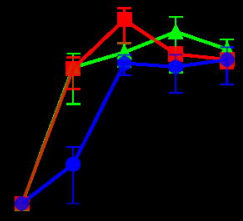

무

- 노

$\Delta$

$\longrightarrow$ 는

는 


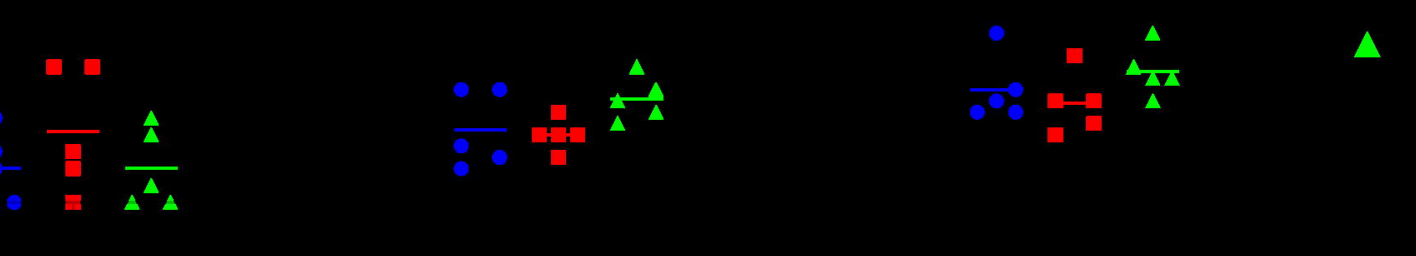
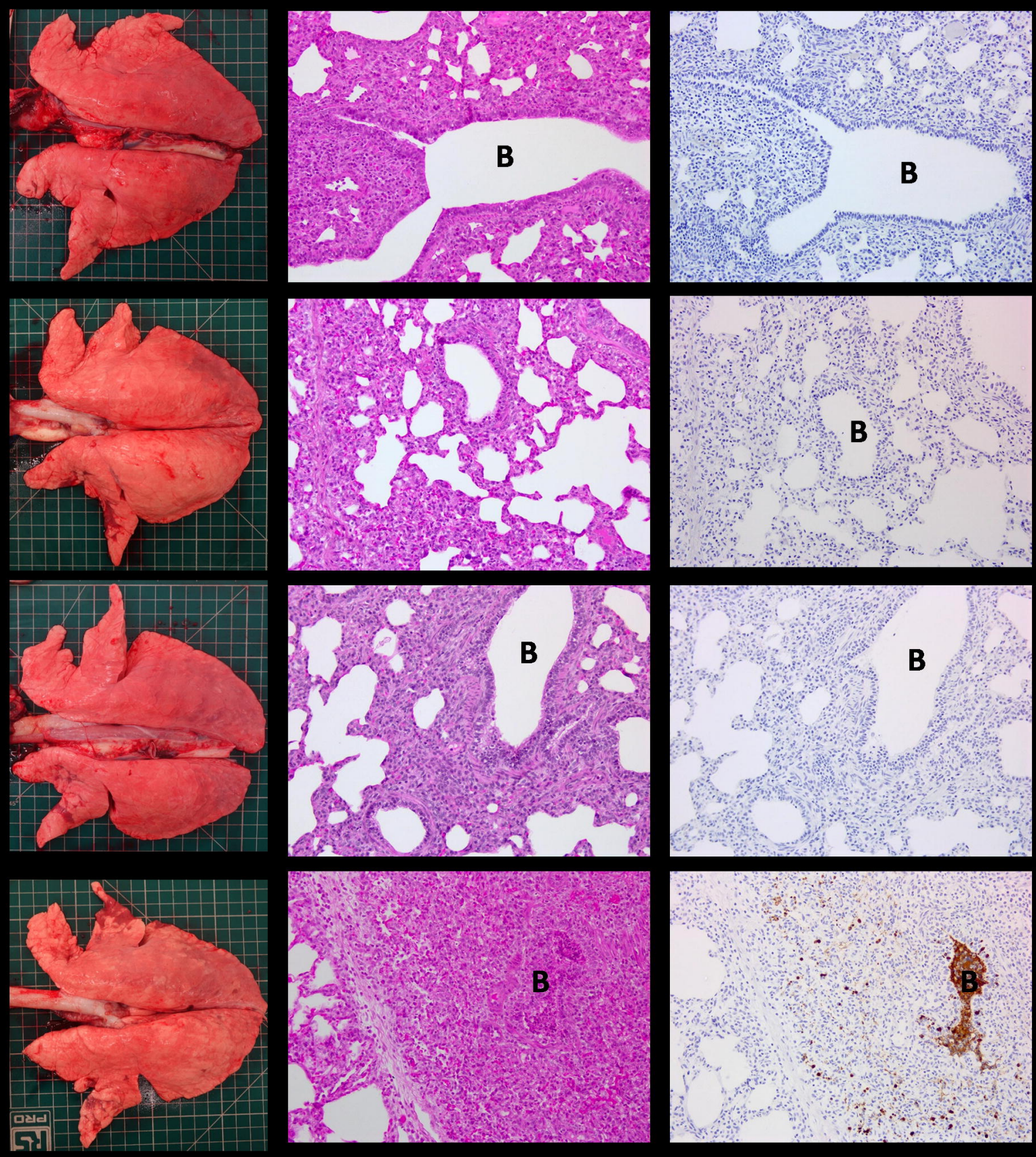

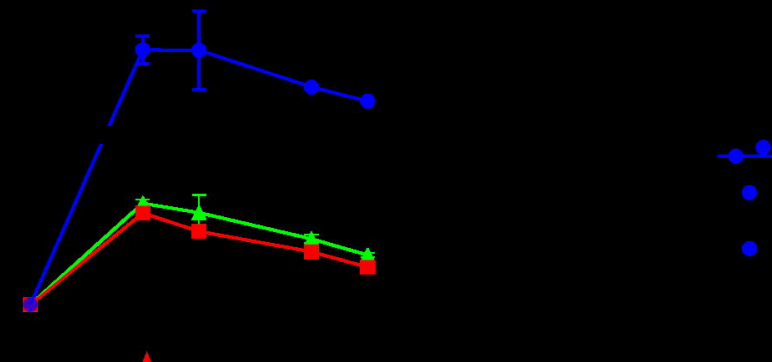

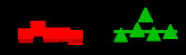

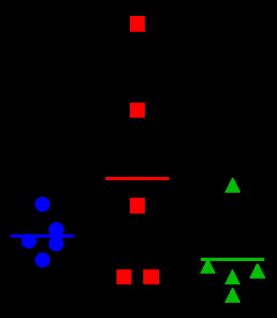

4

H1N1pdm09
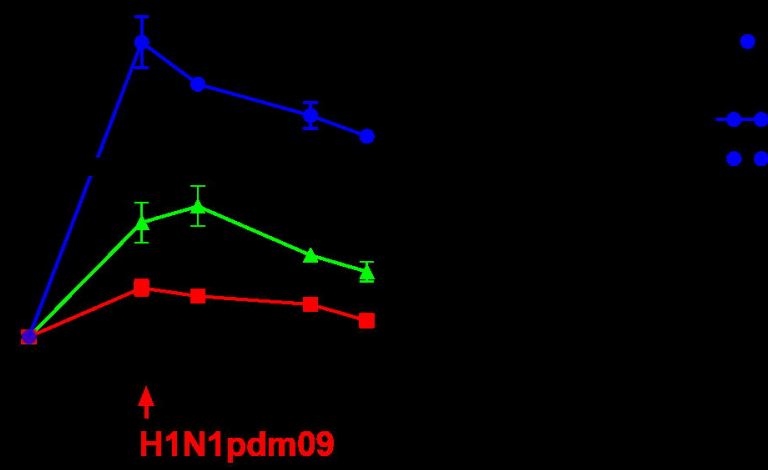

$-\infty$

o c

$-$

$-4$

$\Delta$

$\Delta \Delta$

느소

H1N1pdm09 


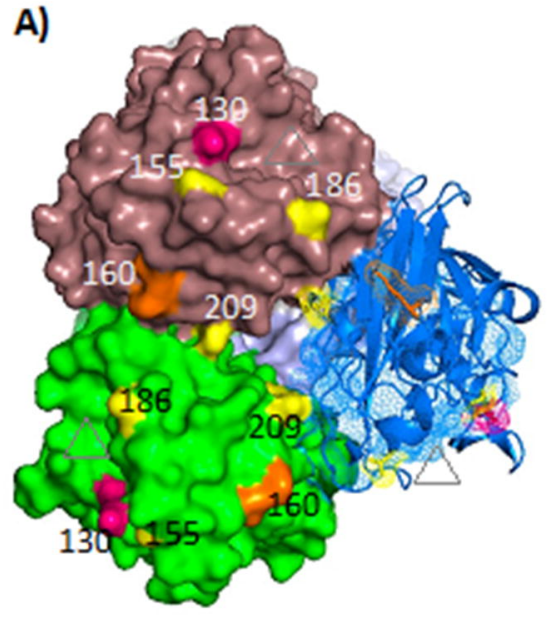

B)

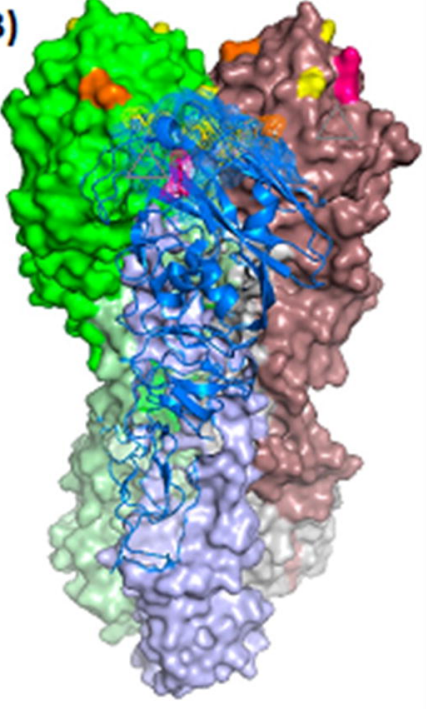

